\title{
Adverse reactions and tolerability of high-dose sublingual allergen immunotherapy
}

\author{
Angel Moral' \\ Victoria Moreno \\ Francisco Girón ${ }^{3}$ \\ David El-Qutob ${ }^{4}$ \\ José D Moure \\ Manuel Alcántara ${ }^{6}$ \\ Antonia Padial ${ }^{7}$ \\ Alberto G Oehling ${ }^{8}$ \\ Carmen Millán" \\ Fernando de la Torre ${ }^{10}$ \\ 'Allergy Service, Hospital Virgen \\ del Valle, Toledo, ${ }^{2}$ Allergy Service, \\ Hospital Blanca Paloma, Huelva, \\ ${ }^{3}$ Consulta Privada, Granada, ${ }^{4}$ Allergy \\ Service, Clínica Atenea, Castellón, \\ ${ }^{5}$ Pediatric Department, Complejo \\ Hospitalario Universitario de Santiago, \\ A Coruña, ${ }^{6}$ Allergy Service, Complejo \\ Hospitalario de Jaén, Jaén, ${ }^{7}$ Allergy \\ Service, Hospital Infanta Sofía, Madrid, \\ ${ }^{8}$ Centro de Alergia y Asma Balear, \\ Mallorca, ${ }^{9}$ Consulta Privada, Cádiz, \\ ${ }^{10}$ ALK-Abelló, SA, Madrid, Spain
}

Correspondence: Fernando de la Torre ALK-Abelló, SA, C/Miguel Fleta 19, 28037 Madrid, Spain

$\mathrm{Tel}+34670627020$

Email Fernando.delatorremartinez@alk.net
This article was published in the following Dove Press journal:

Journal of Asthma and Allergy

29 June 2016

Number of times this article has been viewed

Background: Sublingual allergen immunotherapy is an effective treatment against allergic respiratory disease. Many studies have shown the safety of this type of therapy, although the factors that might affect the tolerability of high-dose sublingual immunotherapy have not been well established. The aim of this study was to determine the factors that affect the tolerability of sublingual allergen immunotherapy.

Patients and methods: $A$ total of 183 subjects aged $\geq 5$ years, diagnosed with allergic rhinitis with/without mild to moderate asthma due to sensitization to grass, olive pollen, or mites, were included in this open, retrospective, multicentric, noninterventional study. Sublingual immunotherapy was administered for at least 3 months.

Results: The most frequent adverse reaction was oral pruritus (13.7\% of the patients). Most of the reactions were local $(84.7 \%)$ and immediate $(93.5 \%)$ and occurred during the initiation phase $(60.6 \%)$. All reactions were mild to moderate in severity. No serious adverse reactions were registered. When comparing factors with potential influence on the occurrence of adverse reactions, the results between the groups of subjects with and without adverse reactions showed no statistically significant differences in sex $(P=0.6417)$, age $(P=0.1801)$, years since the disease was first diagnosed $(P=0.3800)$, treatment composition $(P=0.6946)$, polysensitization $(P=0.1730)$, or clinical diagnosis $(P=0.3354)$. However, it was found that treatment duration had a statistically significant influence ( 3 months, $>3$ months: $P=0.0442$ ) and the presence of asthma was close to statistical significance $(P=0.0847)$.

Conclusion: In our study, treatment duration is significantly associated with the occurrence of adverse reactions after the administration of high doses of sublingual allergen immunotherapy. Keywords: sublingual immunotherapy, tolerability, allergic rhinitis, Olea europaea, grass, Dermatophagoides pteronyssinus

\section{Background}

Sublingual allergen immunotherapy is an effective treatment for allergic respiratory diseases. ${ }^{1,2}$ It has proven to be effective even after completion of the treatment ${ }^{3}$ and prevents the development of asthma in subjects with allergic rhinitis. ${ }^{4}$ Most studies show that it is a safe treatment, even if the administration is initiated by the maintenance dose. ${ }^{5}$ SLITone ${ }^{\text {ULTRA }}$ (ALK-Abelló, SA, Madrid, Spain) is a product containing high concentrations of allergens; its safety and treatment regimen have been previously established. ${ }^{6}$ The factors associated with the occurrence of adverse reactions, besides the dosage, ${ }^{7}$ have not been studied. The aim of this study was to determine the factors linked to this product in a routine clinical setting. 


\section{Methods}

\section{Study design}

This was a noninterventional, observational, multicenter, open-label study carried out with the collaboration of 18 Spanish centers. The study was approved by the Comite Etico de Investigación Clínica del Complejo Hospitalario de Toledo, Toledo, Spain. All study participants (or their legal guardians when younger than 18 years) provided a written informed consent statement.

The study is registered in the European Network of Centres for Pharmacoepidemiology and Pharmacovigilance (ENCePP) database under the code ENCePP/SDPP/6012.

\section{Study population}

The inclusion criteria were diagnosis of allergic rhinoconjunctivitis with/without mild to moderate allergic asthma sensitized to grass, Olea, or house dust mites (Dermatophagoides pteronyssinus/Dermatophagoides farinae); positive skin prick test (wheal diameter $\geq 3 \mathrm{~mm}$ ); and/or positivity to a specific $\operatorname{IgE}$ ( $\operatorname{IgE} \geq$ class 2 ) according to the clinical routine of each investigator. Patients had to be treated with SLITone ${ }^{\text {ULTRA®}}$ for at least 3 months before being included in the study.

The exclusion criteria were patients participating in any clinical trial or research.

\section{Treatment}

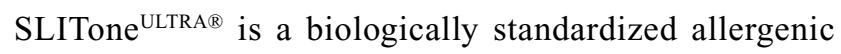
extract presented in a single-dose container of 50 standardized reactivity units (SRU), $150 \mathrm{SRU}$, and $300 \mathrm{SRU}$.

The treatment schedule for the allergens included in this study is as follows:

- Initiation: $50 \mathrm{SRU} /$ day for five consecutive days followed by 150 SRU/day for five additional consecutive days.

- Maintenance: 300 SRU/day (once a day). The treatment should be followed for at least 3 months.

The active ingredients included in this study were pollens $(100 \%$ grass, $100 \%$ olive, or grass + Olea europaea $)$ or mites (D. pteronyssinus or D. pteronyssinus $+D$. farinae).

\section{Assessments}

The possible factors associated with the occurrence of adverse reactions were classified into three groups as follows:

- patient related: age and sex;

- disease related (allergy): clinical diagnosis, presence of asthma, polysensitization, and years since the patient was first diagnosed; and
- treatment related: immunotherapy composition and treatment phase.

Assessment of tolerability was performed by analyzing the adverse reactions (local or systemic) included in the medical history of patients. These reactions were coded as per the Medical Dictionary for Regulatory Activities Version 14.0; they were classified as either immediate ( $0-30$ minutes after the administration of the immunotherapy) or delayed ( $>30$ minutes post administration), local or systemic, and mild (temporary symptoms with no effect on patient's everyday activities), moderate (notable symptoms, moderately affecting patient's everyday activities), or severe (symptoms affecting the patient's everyday activities considerably: unacceptable).

A secondary aim of this study was to assess the degree of compliance and the degree of satisfaction with the product. For this, the Morisky-Green test and the Treatment Satisfaction with Medicine Questionnaire were applied, respectively.

\section{Calculation of sample size and statistical analysis}

Based on previous studies with SLITone ${ }^{\text {ULTRA }}, 8$ from which it was determined that $53 \%$ of the study subjects experienced adverse events (AEs), it was estimated that the percentage of subjects without exposure to a particular factor was somewhat lower ( $\sim 50 \%)$. Thus, a study designed with 200 subjects, with $5 \%$ level of significance and $80 \%$ of power, would allow us to determine the factors causing an increase of $>10 \%$ in the AEs.

The main objective of the study was to detect the risk factors associated (or not) with AEs. For this, the following equation was used:

Incidence of AEs: proportion of patients who had undergone any AE during the treatment.

$$
\frac{\text { Number of patients with any adverse event }}{\text { Total number of patients }}
$$

A univariate model was constructed for each possible risk factor. Significant factors were included ( $10 \%$ of significance) and were used along with their possible interactions to develop a multivariate logistic regression model.

\section{Results}

A total of 183 study subjects were included in the study, of whom 8 were not considered in the analyses because they did not meet the inclusion criteria: 6 due to treatment duration ( $<3$ months once included in the study) and 2 for being younger than 5 years. 
Of the 175 study subjects included in the analysis, $54.3 \%$ were women with a mean age of $21.2 \pm 15.5$ years. All had allergic rhinitis and 93 (53.1\%) also suffered from allergic asthma; $50.6 \%$ were polysensitized. The treatment composition for the study subjects (n/\%) was as follows: $100 \%$ grass 30 subjects $(18.0 \%), 100 \%$ Olea 32 subjects $(19.2 \%)$, grass + Olea 39 subjects (23.4\%), Dermatophagoides mix 32 subjects (19.2\%), and D. pteronyssinus 34 subjects (20.4\%). The mean treatment duration was 6.8 months, with a minimum of 3 months and a maximum of 52 months. One hundred and eighteen patients $(68.6 \%)$ received concomitant medication: oral antihistamines 94 patients $(54.7 \%)$, topical antihistamines 13 patients $(7.6 \%)$, nasal corticosteroids 41 patients (23.8\%), inhaled corticosteroids 34 patients $(19.8 \%)$, oral corticosteroids two patients (1.2\%), $\beta$-2 agonists 32 patients (18.6\%), and antileukotrienes 14 patients (8.1\%).

The adverse reactions registered in the study, coded as per the Medical Dictionary for Regulatory Activities, are shown in Figure 1. The most frequent reaction was oral pruritus ( $13.7 \%$ of study patients). Other AEs occurred in $<5 \%$ of the subjects. Considering all AEs, most were local $(84.7 \%)$ and immediate (93.5\%). A total of $60.6 \%$ of the events occurred at the initiation phase of the treatment, more frequently when the highest dose was administered (67.7\%). All reactions were mild to moderate. No serious adverse reactions were registered. In all, $80.6 \%$ of the events did not require any modification of the treatment plan. Regarding the allergen, D. pteronyssinus, the Dermatophagoides mix, Olea, and grass and grass + Olea were linked to AEs in $2.9 \%, 5.7 \%, 4 \%$, and $5.1 \%$ of the patients, respectively. Tolerance was considered as good or very good in $94.8 \%$ of the subjects.

The causative factors possibly associated with the AEs are summarized in Table 1. Using the logistic regression multivariate model considering the two factors with the greatest influence on the occurrence of AEs (presence of asthma and duration of the treatment), a statistically significant interaction was observed between the two factors $(P=0.0353)$. Thus, the influence of asthma varies depending on the duration of the treatment: in patients who were treated for 3 months, the influence is statistically significant (OR 3.21, 95\% CI $1.27-8.08)$ and in patients who had been treated for $>3$ months, it is not significant (OR $0.56,95 \%$ CI $0.14-2.20$ ).

\section{Discussion}

There are limitations to this study. The first limitation is the small number of patients, which allowed us to detect only the factors that increase the number of AEs to $10 \%$. Previous studies performed with the same product ${ }^{6,8}$ indicated that a value $<10 \%$ would not be clinically relevant.

The second limitation is the noninclusion of patients with allergic sensitization to other allergens different from those analyzed here, which could modify the tolerability pattern. However, the allergens included in this study are the most frequently prescribed allergens in Spain, and using other less prevalent allergens may have reduced the capacity of statistical analysis.

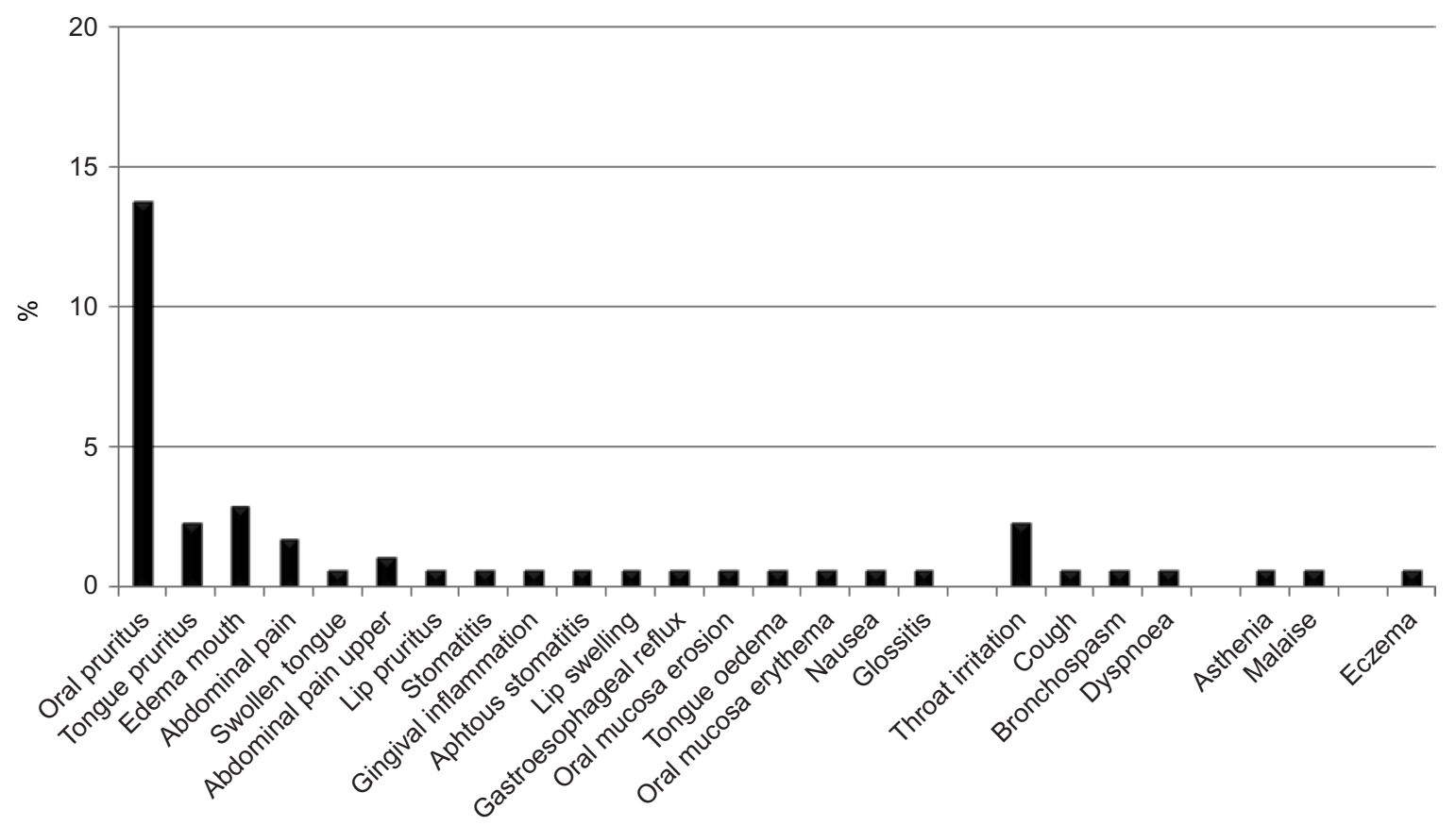

Figure I Description of adverse reactions registered in the study expressed as percentage of patients. 
Table I Influence of different factors in the occurrence of adverse reactions

\begin{tabular}{|c|c|c|c|}
\hline & $\begin{array}{l}\text { Patients without adverse } \\
\text { reactions }\end{array}$ & Patients with adverse reactions & $P$-value \\
\hline \multicolumn{4}{|l|}{ Sex, n (\%) } \\
\hline Female & $72(75.8 \%)$ & $23(24.2 \%)$ & 0.6417 \\
\hline Male & $63(78.8 \%)$ & $17(2 \mid .3 \%)$ & \\
\hline \multicolumn{4}{|l|}{ Age groups, n (\%) } \\
\hline $5-9$ years & $30(75.0 \%)$ & $10(25.0 \%)$ & 0.1801 \\
\hline $10-29$ years & $66(73.3 \%)$ & $24(26.7 \%)$ & \\
\hline $30-76$ years & $39(86.7 \%)$ & $6(13.3 \%)$ & \\
\hline Time since the disease was diagnosed (years), median (QI, Q3) & $4.0(3.0,9.0)$ & $5.0(3.0,10.0)$ & 0.3800 \\
\hline \multicolumn{4}{|l|}{ Asthma, n (\%) } \\
\hline Yes & $67(72.0 \%)$ & $26(28.0 \%)$ & 0.0847 \\
\hline No & $68(82.9 \%)$ & $14(17.1 \%)$ & \\
\hline \multicolumn{4}{|l|}{ Clinical diagnosis, n (\%) } \\
\hline Rhinitis, conjunctivitis, and asthma & $38(70.4 \%)$ & $16(29.6 \%)$ & 0.3354 \\
\hline Rhinitis and asthma & 29 (74.4\%) & $10(25.6 \%)$ & \\
\hline Rhinitis and conjunctivitis & $34(81.0 \%)$ & $8(19.0 \%)$ & \\
\hline Rhinitis & $34(85.0 \%)$ & $6(15.0 \%)$ & \\
\hline \multicolumn{4}{|l|}{ Composition of immunotherapy, $n$ (\%) } \\
\hline Grass & $21(70.0 \%)$ & $9(30.0 \%)$ & 0.6946 \\
\hline O. europaea & $26(81.3 \%)$ & $6(18.8 \%)$ & \\
\hline Grass + O. europaea & 29 (74.4\%) & $10(25.6 \%)$ & \\
\hline Dermatophagoides mix & 23 (71.9\%) & $9(28.1 \%)$ & \\
\hline D. pteronyssinus & $28(82.4 \%)$ & $6(17.6 \%)$ & \\
\hline \multicolumn{4}{|l|}{ Duration of treatment with SLITone ${ }^{\mathrm{ULTRA}}, \mathrm{n}(\%)$} \\
\hline 3 months & 78 (72.2\%) & $30(27.8 \%)$ & 0.0442 \\
\hline$>3$ months & $57(85.1 \%)$ & $10(14.9 \%)$ & \\
\hline \multicolumn{4}{|l|}{ Sensitization, $\mathrm{n}(\%)$} \\
\hline Monosensitized & 70 (8I.4\%) & $16(18.6 \%)$ & 0.1730 \\
\hline Polysensitized & $64(72.7 \%)$ & $24(27.3 \%)$ & \\
\hline \multicolumn{4}{|l|}{ Concomitant medication, $\mathrm{n}(\%)$} \\
\hline Yes & 89 (75.4\%) & $29(24.6 \%)$ & 0.5411 \\
\hline No & 43 (79.6\%) & II (20.4\%) & \\
\hline
\end{tabular}

Note: The values in bold italic mean values are statistically significant or close to statistical significance.

Abbreviations: O. europaea, Olea europaea; D. pteronyssinus, Dermatophagoides pteronyssinus.

A third limitation is the design of the study; observational studies are considered to be at greater risk of bias. On the other hand, observational studies allow including children and adults, and we considered that age was an important factor to consider.

The aim of our study was to determine the risk factors associated with SLITone ${ }^{\text {ULTRAB }}$ tolerance in patients treated during the clinical practice. We found that treatment duration and asthma were the factors with the highest influence. In a previous study with other product administered sublingually, eg, GRAZAX ${ }^{\circledR}$, it has been found that the occurrence of AEs is more frequently early in the treatment and tends to decrease. ${ }^{9}$ On the other hand, a previous study performed with sublingual immunotherapy tablets showed that in patients with asthma and rhinoconjunctivitis, this treatment is safe and well tolerated. ${ }^{10}$ Another possible factor may be the type of allergen administered. For this study, we used the most common allergens in our country, and no differences in tolerance between them were observed. Similarly, no effect was seen with other factors with potential influence, such as the age of the study subject, clinical diagnosis, or polysensitization.

The tolerability observed in our study is similar to that communicated in previous trials. Oral pruritus was the only adverse reaction registered in $>10 \%$ of the study patients, and all AEs were mild to moderate in severity. For many years, the good safety profile of sublingual immunotherapy was attributed to the use of extracts with low allergen concentration. However, recent investigations have established that the oral mucosa contains few or no mast cells, eosinophils, or basophils, and the integrity of the lamina propria is crucial for a limited contact between the allergen and the previously mentioned cells. This explains the good safety profile of products with a high allergen concentration. ${ }^{11}$ On the other hand, the oral mucosa is rich in Langerhans-like dendritic cells expressing high affinity to the IgE receptor and toll-like 
receptors. Following activation of these receptors, the cells produce IL-10 and TGF- $\beta$, indicating that these cells are crucial in maintaining allergen tolerance. ${ }^{11,12}$

\section{Conclusion}

Our results indicate that SLITone ${ }^{\mathrm{ULTRA}}{ }^{\circledR}$ has a good safety profile. The duration of the treatment with this product seems to be the primary factor associated with the occurrence of AEs. However, studies with a larger number of patients have to be designed.

\section{Acknowledgments}

The authors gratefully acknowledge the following individuals for their contributions as main investigators to this project: Carlos Sánchez-Salguero (Clínica Ntra Sra de la Salud, Cádiz, Spain), Javier Hernández-Arbeiza and Soledad JiménezTimón (Hospital Ntra Sra de la Montaña, Cáceres, Spain), Nuria Rubira (Can Mora, Sant Cugat, Barcelona, Spain), Rafael Calderón and $\mathrm{M}^{\mathrm{a}}$ José Palao (Hospital de Manises, Valencia, Spain), Leire Dopazo (Hospital de Cruces, Vizcaya, Spain), Luis Fernández-Moya (Hospital de Llerena-Zafra, Badajoz, Spain), Benito Rodríguez (Hospital de Manzanares, Ciudad Real, Spain), José Vigaray (Consulta Privada, Madrid, Spain), Pilar Sánchez-Pallá (Hospital del Río Hortega, Valladolid, Spain), and $\mathrm{M}^{\mathrm{a}}$ José Pascual (Centro de Alergia y Asma Balear, Mallorca, Spain). The statistical analysis and technical support was carried out by BioClever (CRO, Barcelona, Spain). The study has been supported by ALK-Abelló, S.A.

\section{Author contribution}

Inclusion of the patients was done by all authors (except FDLT). All authors contributed toward data analysis, drafting and critically revising the paper and agree to be accountable for all aspects of the work. All authors also approved the final paper.

\section{Disclosure}

Fernando de la Torre is employed at ALK-Abelló, SA. The other authors report no conflicts of interest in this work.

\section{References}

1. Wilson DR, Lima MT, Durham SR. Sublingual immunotherapy for allergic rhinitis: systematic review and meta-analysis. Allergy. 2005; 60(1):4-12.

2. Penagos M, Passalacqua G, Compalati E, et al. Metaanalysis of the efficacy of sublingual immunotherapy in the treatment of allergic asthma in pediatric patients, 3 to 18 years of age. Chest. 2008;133(3): 599-609.

3. Di Rienzo V, Marcucci F, Puccinelli P, et al. Long-lasting effect of sublingual immunotherapy in children with asthma due to house dust mite: a 10-year prospective study. Clin Exp Allergy. 2003;33(2):206-210.

4. Novembre E, Galli E, Landi F, et al. Coseasonal sublingual immunotherapy reduces the development of asthma in children with allergic rhinoconjunctivitis. J Allergy Clin Immunol. 2004;114(4):851-857.

5. Rodríguez F, Boquete M, Ibáñez MD, de la Torre-Martínez F, Tabar AI. Once daily sublingual immunotherapy without updosing. A new treatment schedule. Int Arch Allergy Immunol. 2006;140(4):321-326.

6. Nittner-Marszalska M, Fayoux E, Chartier A, Strodl Andersen J, Kuna P. Sublingual solution for immunotherapy: comparison of three different up-dosing schedules. Rev Fr Allergol. 2013;53(2):65-72.

7. Gidaro GB, Marcucci F, Sensi L, Incorvaia C, Frati F, Ciprandi G. The safety of sublingual-swallow immunotherapy: an analysis of published studies. Clin Exp Allergy. 2005;35(5):565-571.

8. Didier A, Campo P, Moreno F, et al. Dose-dependent immunological response after a 6-month course of sublingual house dust mite immunotherapy in patients with allergic rhinitis. Int Arch Allergy Immunol. 2015;168:182-192

9. Kleine-Tebbe J, Ribel M, Herold DA. Safety of a SQ-standardised grass allergen tablet for sublingual immunotherapy: a randomized, placebocontrolled trial. Allergy. 2006;61(2):181-184.

10. Calderón M, Essendrop M. Specific immunotherapy with high dose SO standardized grass allergen tablets was safe and well tolerated. $J$ Investig Allergol Clin Immunol. 2006;16(6):338-344.

11. Moingeon P, Batard T, Fadel R, Frati F, Sieber J, van Overtvelt L. Immune mechanism of allergen-specific sublingual immunotherapy. Allergy. 2006;61(2):151-165.

12. Novak N, Allam JP. Mucosal dendritic cells in allergy and immunotherapy. Allergy. 2011;66(suppl 95):22-24.
Journal of Asthma and Allergy

\section{Publish your work in this journal}

The Journal of Asthma and Allergy is an international, peer-reviewed open access journal publishing original research, reports, editorials and commentaries on the following topics: Asthma; Pulmonary physiology; Asthma related clinical health; Clinical immunology and the immunological basis of disease; Pharmacological interventions and

\section{Dovepress}

new therapies. This journal is included in PubMed. The manuscript management system is completely online and includes a very quick and fair peer-review system, which is all easy to use. Visit http://www. dovepress.com/testimonials.php to read real quotes from published authors. 